AGH DRILLING, OIL, GAS • Vol. 33 • No. $1 \cdot 2016$

http://dx.doi.org/10.7494/drill.2016.33.1.173

\author{
Sławomir Wysocki*, Kinga Klima**, \\ Agnieszka Podborska****
}

\title{
STUDIES ON THE IMPACT OF IONIC DEGREE OF COPOLYMER POLY(AAm-CO-AMPSA) TO BENTONITE SUSPENSION PARAMETERS*****
}

\section{INTRODUCTION}

Modified starch was the first applied polymer in drilling liquids technology. It was used to reduce filtration of muds. It took place at the turn of 20 s and 30 s. The first synthetic water-soluble polymers began to apply in drilling in the middle of $50 \mathrm{~s}$ of the $20^{\text {th }}$ century. Its aim was to improve rheological properties of bentonite suspension and stability of the hole surface. Since then, there was a constant growth in importance of polymers in drilling liquids technology [1-3].

The list of functions that polymers fulfill in drilling fluids is long. Polymers are applied among others: to adjust rheological parameters, reduce filtration, as hydration inhibitors of clay rocks, flocculants, etc. [2].

The direction of polymer effect in drilling fluid mainly depends on two mechanisms: adsorption on particulates and changes of the viscosity system. In addition, the adsorption mechanism is decisive [2].

Adsorption of large molecules with chain structure is very complex and depends on many factors: adsorbent area, polymer concentration, its particle mass, $\mathrm{pH}$ and strength

* AGH University of Science and Technology, Faculty of Drilling, Oil and Gas, Krakow, Poland

** AGH University of Science and Technology, Faculty of Drilling, Oil and Gas, Krakow, Poland - student

*** AGH University of Science and Technology, Faculty of Non-Ferrous Metals, Krakow, Poland **** Paper prepared within the statutory research program of the Faculty of Drilling, Oil and Gas, AGH University of Science and Technology No. 11.11.190.555 
of ionic suspension [2]. Polymer structure has an important role, in particular quantity and quality of functional groups in side chains and size of these chains (steric hindrance).

Therefore, there are widely conducted studies on the application of new polymers in drilling fluid technologies.

This article presents results of the laboratory studies on the impact of ionic degree of copolymer poly(AAm-co-AMPSA) to technological parameters of bentonite suspension. Synthesized polymers of poly(AAm-co-AMPSA) are low-molecular anionic and nonionic copolymers. In side chains contains anionic $\mathrm{SO}_{3}^{-}$groups with high steric hindrance and nonionic amide groups with low steric hindrance. Synthesized polymers differed by mers ratio in the chain, i.e. ionic degree.

\section{REAGENTS APPLIED IN STUDIES}

AAm - acrylamide [CAS 79-06-1], >98\%, Fluka; AMPSA - 2-acrylamido-2-methyl1-propanesulfonic acid [CAS 15214-89-8], 99\%, Aldrich; AIBN - 2,2'-azobis(2-methylpropionamidine)dihydrochloride [CAS 2997-92-4], 97\%, Aldrich; Bentonite - Bentopol Zębiec - technical grade.

\section{POLYMER SYNTHESIS}

Syntheses of polymers were conducted in the water solution. Dissolved monomers (AAm, AMPSA) and initiator (AIBN) were placed in three necked flask with reflux condenser. Syntheses were conducted at a temperature of $700^{\circ} \mathrm{C}$ for 7 hours. Polymer solution was cooled down, and then applied as received. Polymer concentration in solution was $5 \% \mathrm{w} / \mathrm{w}$.

As a result of conducted syntheses, three copolymers were obtained, which differed by mers ratio, and consequently also with ionic degree. Polymers were determined as KK-33, KK-25, KK-10, where the number indicates ionic degree:

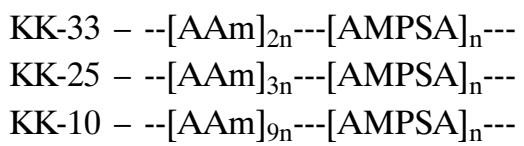

Ionic degree is defined as a percentage ratio of the quantity of ion groups to the quantity of all groups in polymer side chains.

Synthesized polymers are characterized by low particle mass. In side chains they contain anionic sulphonic groups from mers 2-acrylamido-2-methyl-1-propanesulfonic acid (Fig. 1b) and nonionic group from acrylamide (Fig. 1a). AMPSA mers are characterized by high steric hindrance, and AAm mers by low steric hindrance. 
a)

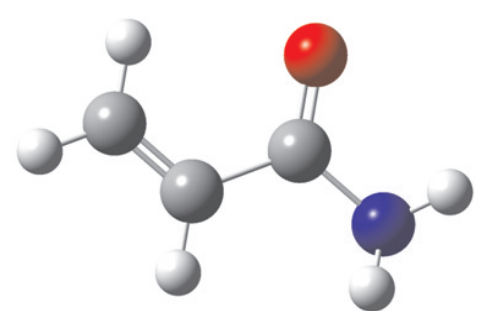

b)

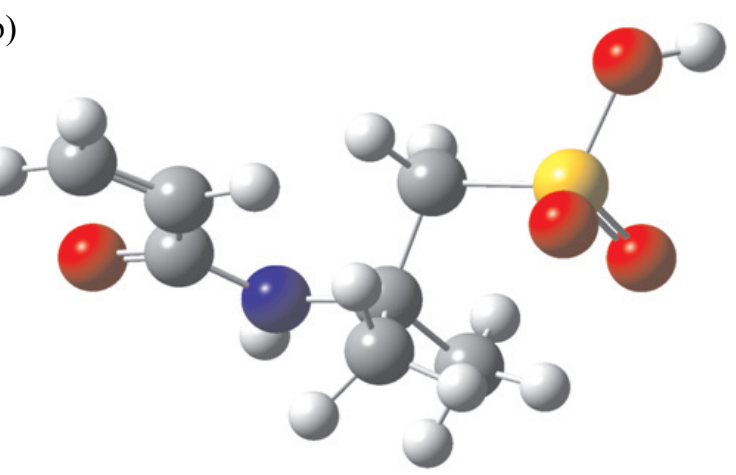

Fig. 1. Monomers: a) AAm, b) AMPSA

\section{FTIR STUDIES OF SYNTHESIZED POLYMERS}

Synthesized copolymer was characterized using technology of the adsorptive spectroscopy in infrared in order to confirm polymerizational nature of the reaction, as well as in order to analyze the copolymer structure.

Examination was carried out using FT-IR TENSOR spectrometer of Bruker II Company. However, measurements were conducted on Attenuated Total Reflection attachment with diamond crystal. Obtained hydrogel before measurement was shaken in order to avoid suppression of the energy spectrum analysis by dominant water spectrum. The scope of research for both AAm and AMPS is located within the limits of 4000-450 $\mathrm{cm}^{-1}$, which qualifies the given research method to subgroup of so-called infrared proper $4000-400 \mathrm{~cm}^{-1}$. Study results for polymer poly(AAm-co-AMPSA), marked as KK-33, were presented in Figures 2-5.

Standard peaks of groups $\mathrm{N}=\mathrm{H}$ were observed in the scope of $659-815 \mathrm{~cm}^{-1}$, which is characteristic for acrylamide. $1034 \mathrm{~cm}^{-1}$ constitutes AMPSA characteristics, caused by $\mathrm{S}=\mathrm{O}$ group. Regular and symmetrical as well as asymmetrical $\mathrm{SO}_{2}$ oscillation can also be observed in the range of $1202 \mathrm{~cm}^{-1}$.

The most intense peak of $\mathrm{C}=\mathrm{O}$ from both AAm and AMPSA is clarified at the value of $1650 \mathrm{~cm}^{-1}$. Observation of so-called absorption peak in the range of $1650-1666 \mathrm{~cm}^{-1}$ constitutes carboxamide identifier.

Numerous deformations of the amino group cause disruption in the range of 1545 and $3000 \mathrm{~cm}^{-1}$.

Sudden and constant growth of the absorption above $3000 \mathrm{~cm}^{-1}$ is associated with a presence of hydroxyl groups and related sulphonic groups.

Based on the analysis of energy spectrum it is possible to come to hypothesis that in examined copolymer the monomeric units are located randomly along the chain (statistical copolymer) and reaction initiator in AIBN form was used in excess. 


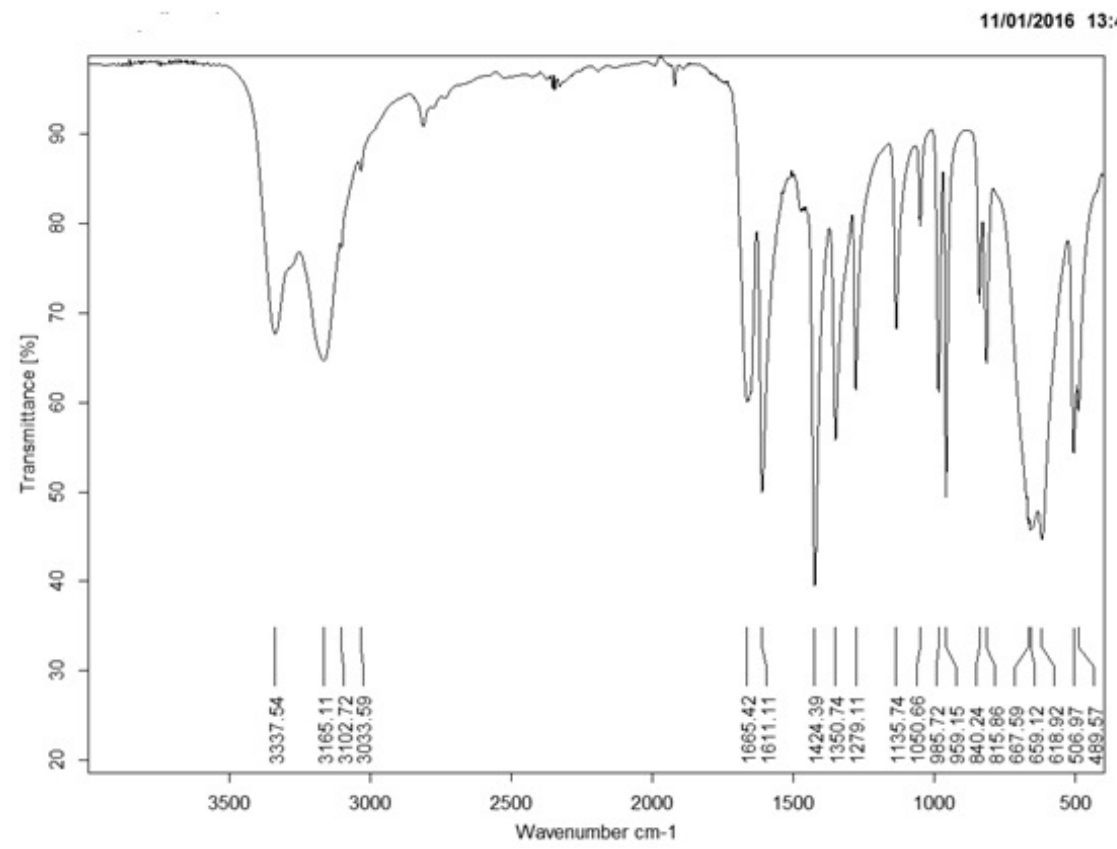

Fig. 2. The IR spectrum of acrylamide (AAm)

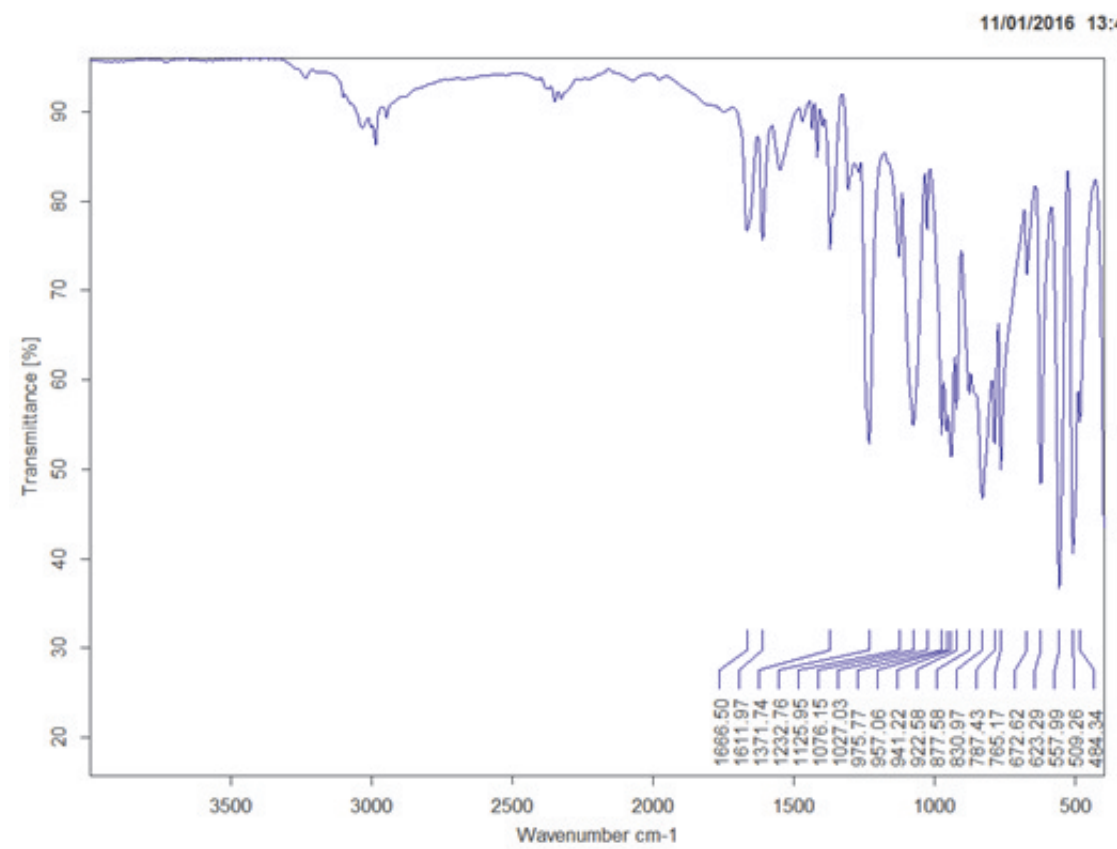

Fig. 3. The IR spectrum of 2-acrylamido-2-methyl-1-propanesulfonic acid (AMPSA) 


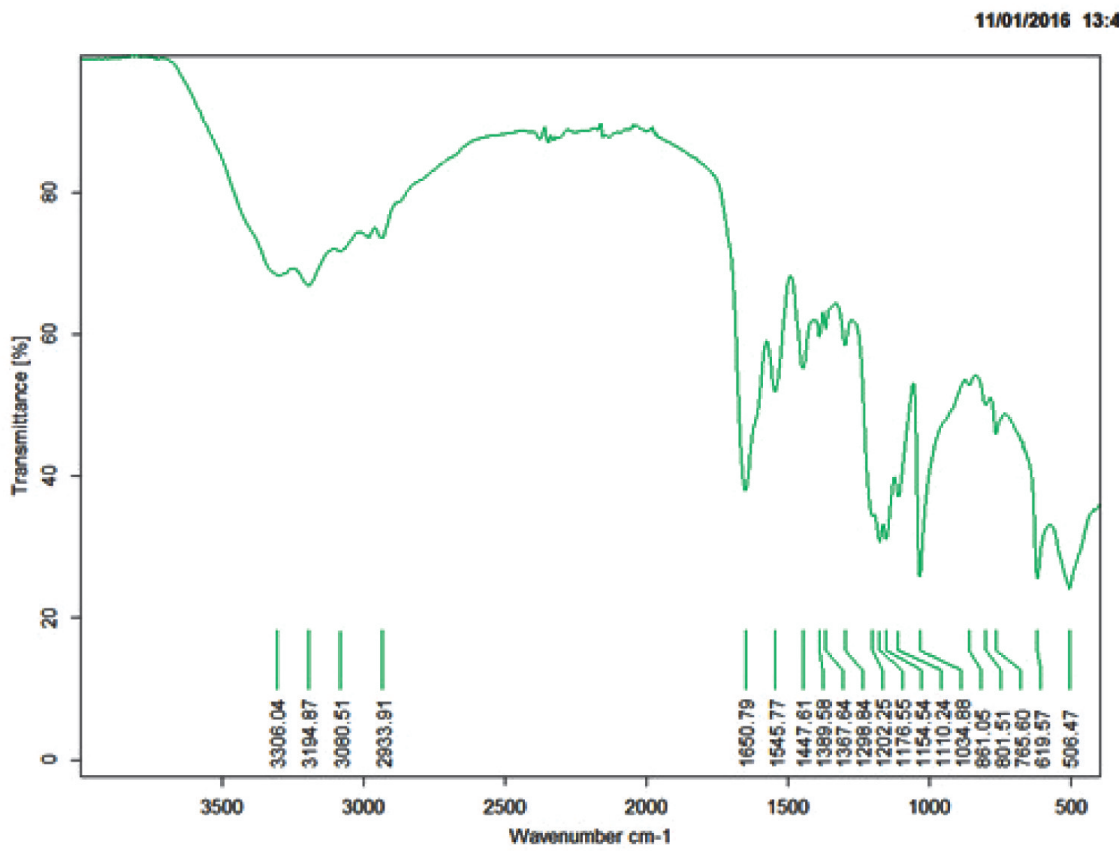

Fig. 4. The IR spectrum of copolymer poli(AAm-co-AMPSA) - KK-33

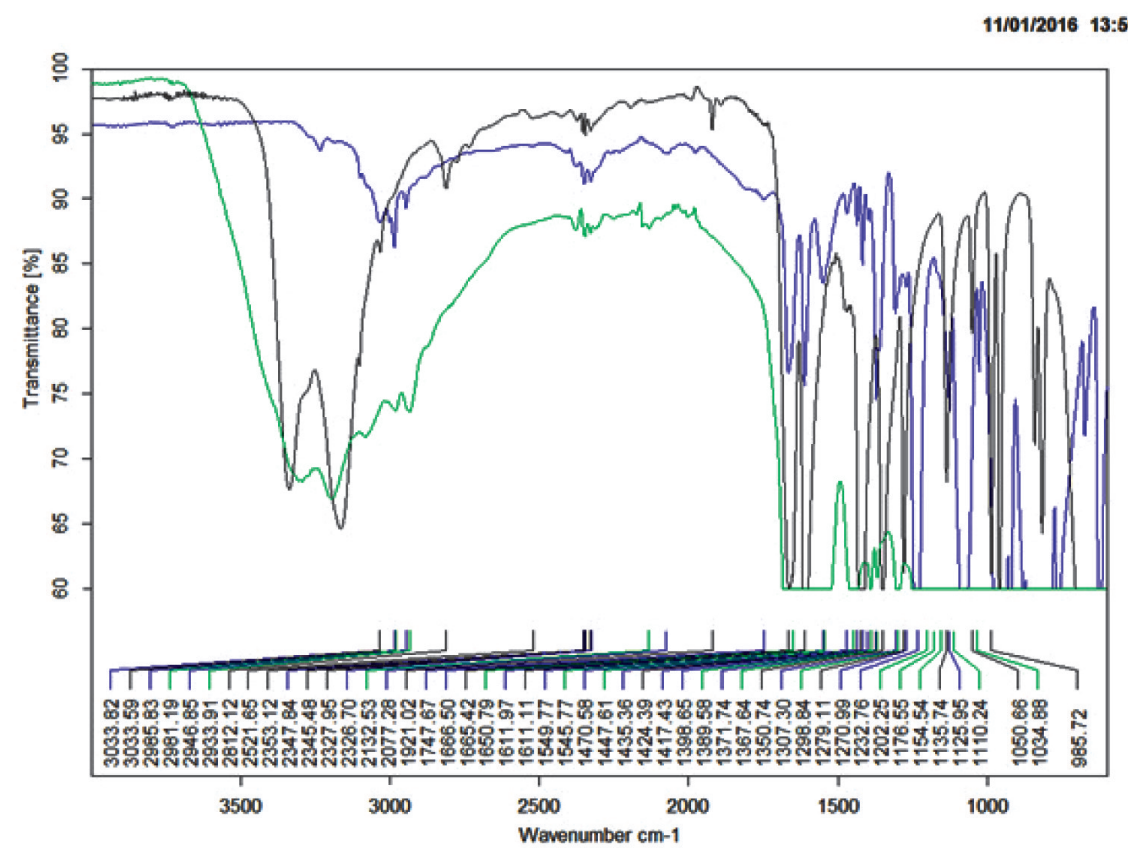

Fig. 5. The IR spectrum of copolymer poli(AAm-co-AMPSA) KK-33 and monomers 


\section{STUDIES ON THE IMPACT OF IONIC SYNTHESIZED COPOLYMERS TO BENTONITE SUSPENSION PARAMETERS}

An examination of the impact of ionic synthesized copolymers to bentonite suspension parameters was carried out. For that purpose a bentonite suspension was conducted, and then the polymer was added to it in different concentrations and stirred for $30 \mathrm{mi}-$ nutes. Final bentonite concentration was $3 \% \mathrm{w} / \mathrm{w}$. Suspension was conditioned for 24 hours. Compositions of examined suspensions were presented in Table 1.

Table 1

Composition of tested mud [\%]

\begin{tabular}{|l|c|c|c|c|c|c|c|}
\cline { 2 - 8 } \multicolumn{1}{c|}{} & Mud-0 & Mud-1 & Mud-2 & Mud-3 & Mud-4 & Mud-5 & Mud-6 \\
\cline { 2 - 8 } \multicolumn{1}{c|}{} & 3 & 3 & 3 & 3 & 3 & 3 & 3 \\
\hline KK-10 & - & 0.25 & - & - & 1 & - & - \\
\hline KK-25 & - & - & 0.25 & - & - & 1 & - \\
\hline KK-33 & - & - & - & 0.25 & - & - & 1 \\
\hline
\end{tabular}

Next, studies of technological parameters were conducted according to international norms of American Petroleum Institute (API) [4]. Rheological properties of bentonite suspension, lubricity and filtration were examined. Research results were presented on graphs (Figs 6-11).

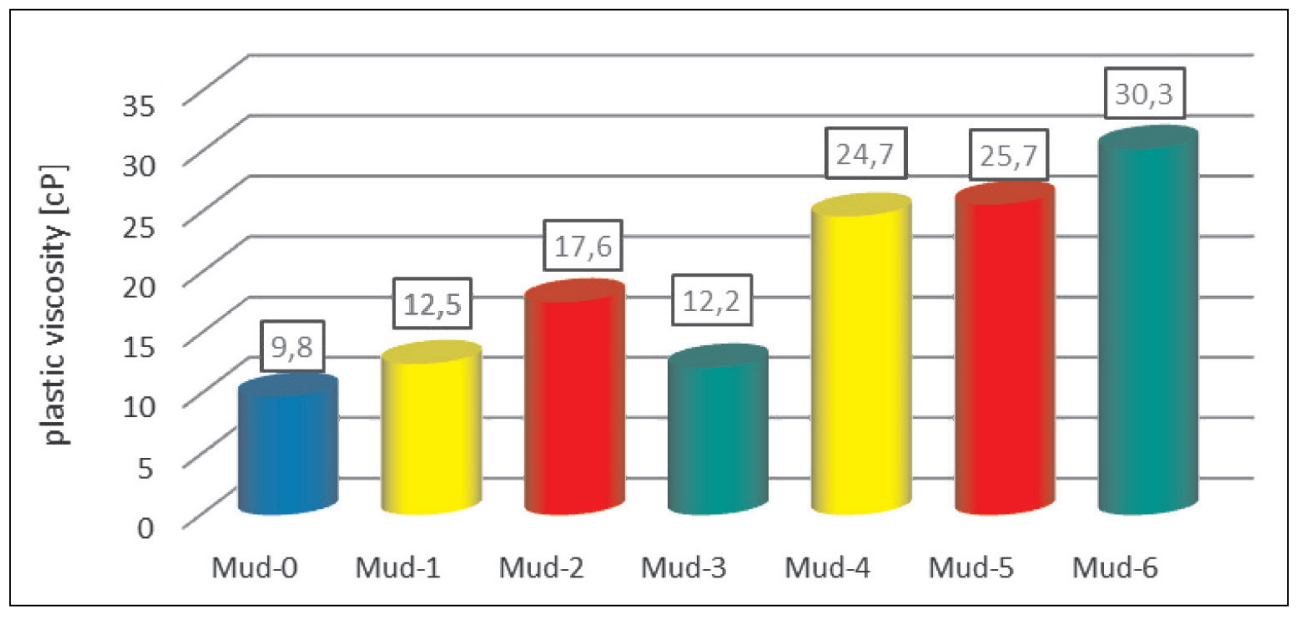

Fig. 6. Plastic viscosity of tested mud 


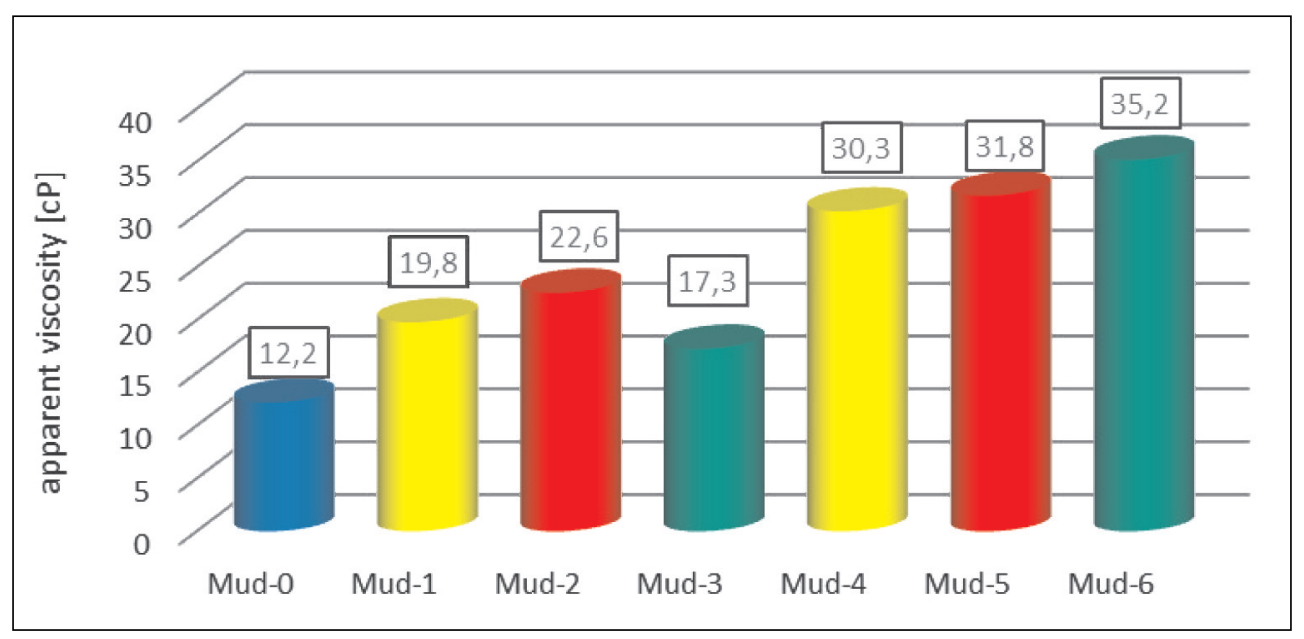

Fig. 7. Apparent viscosity of tested mud

Conducted examinations showed that addition of synthesized copolymers causes an increase in number of plastic viscosity (Fig. 6) and apparent viscosity (Fig. 7) of bentonite suspension. For low copolymer concentrations (Mud-1-3) the highest increase in PV and AV value was noted for KK-25 polymer. In case of polymers use in high viscosity concentrations (Mud-4-6), they increase with ionic height of copolymers.

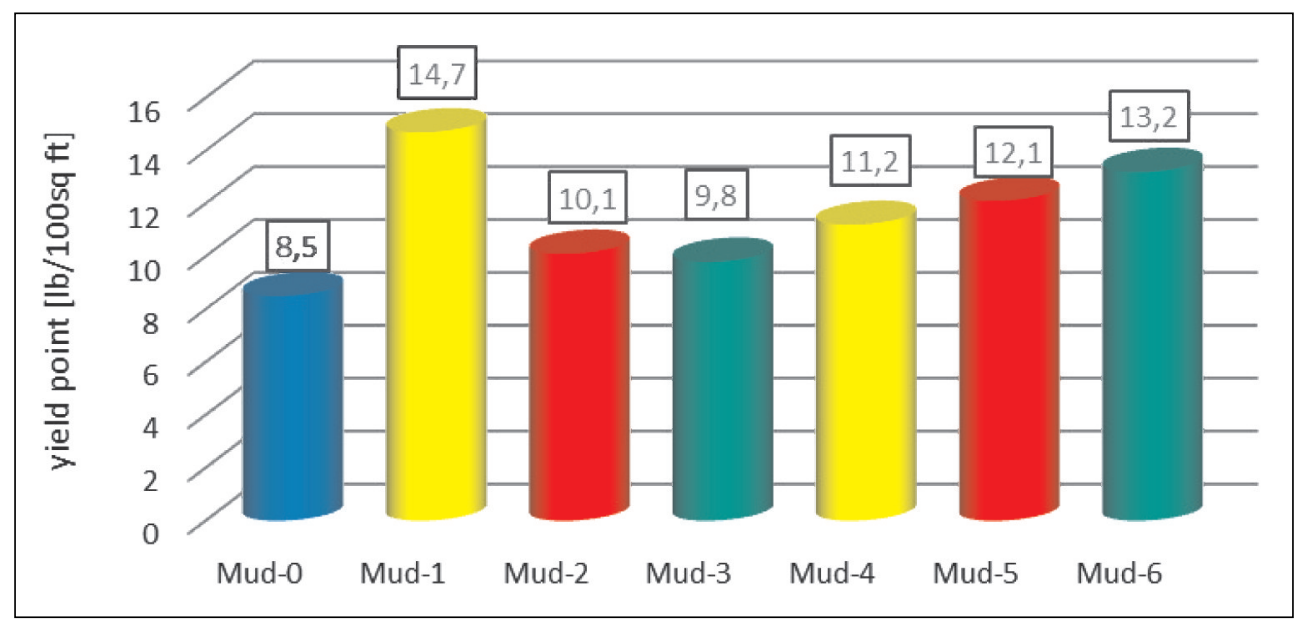

Fig. 8. Yield point of tested mud

All examined polymers increase flow limits of bentonite suspension (Fig. 8). It was found that for low concentrations of studied copolymers a flow limit decreases along with ionic height of polymer. For high copolymer concentrations an opposite effect is observed. 


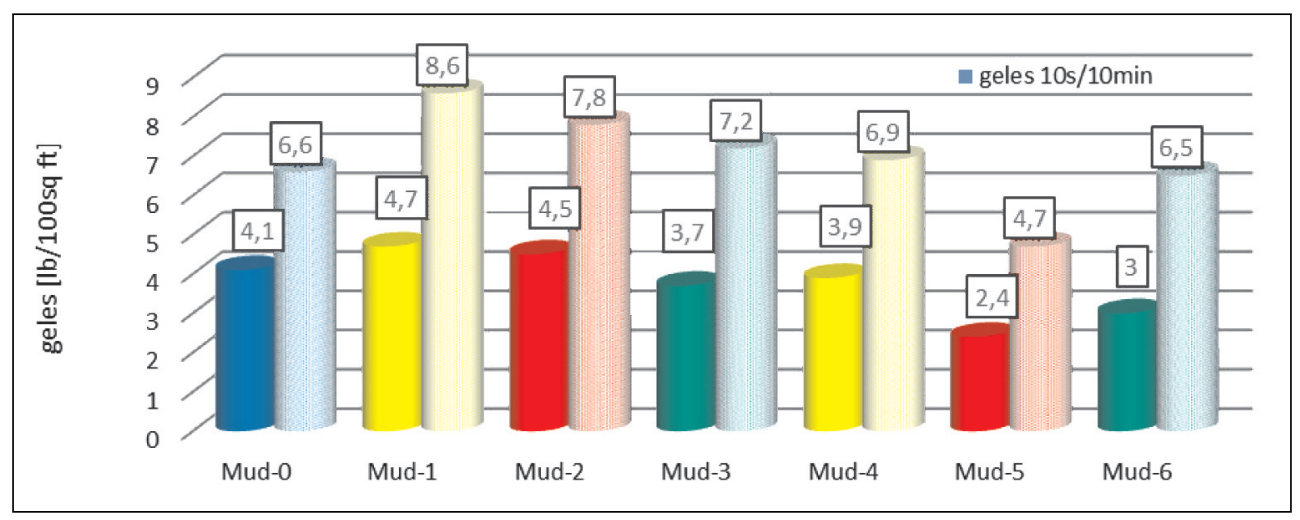

Fig. 9. Geles of tested mud

Conducted examinations showed that in low concentrations, examined copolymers caused an increase in the second structural strength (Fig. 9). The height is lower for polymers with higher ionic. A similar effect was observed for the first structural strength; however for KK-33 polymer the value of this strength drops below the value recorded for suspension without the addition of polymer. An increase in polymer concentration causes decrease in the structural strength of bentonite suspension. In this case a correlation from ionic of polymer wasn't observed.

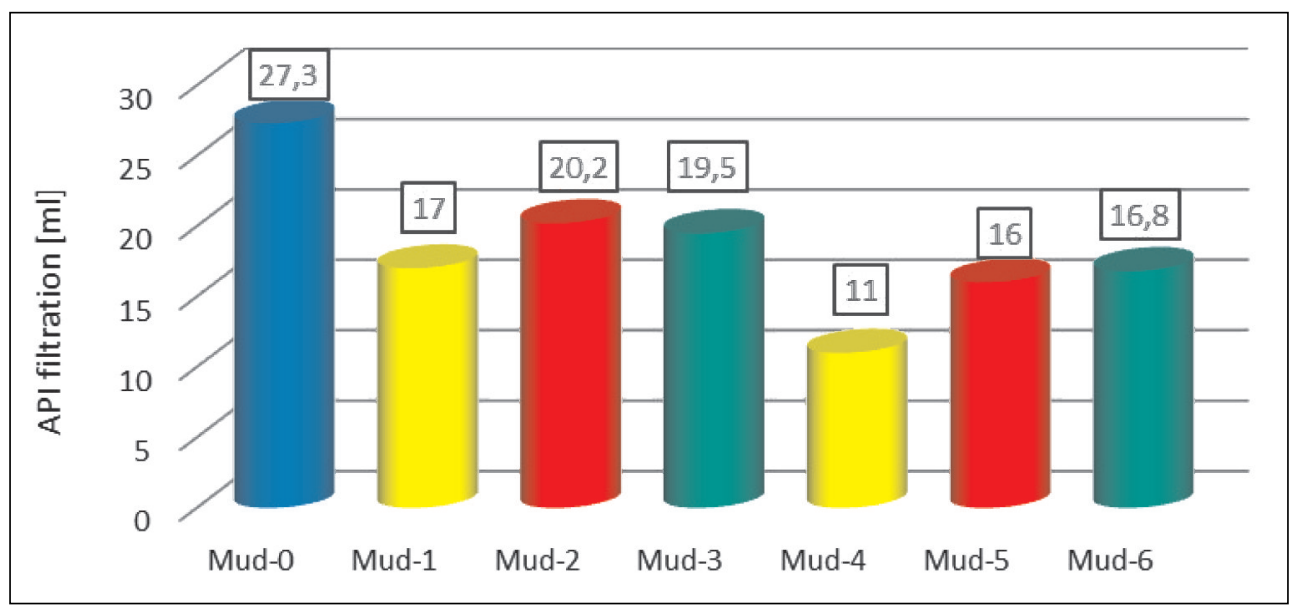

Fig. 10. API filtration of tested mud

Examined copolymers have a positive impact on reduction in values of bentonite suspension filtration (Fig. 10). The best result was noted for polymer with the lowest ionic, irrespective of copolymer concentration. 


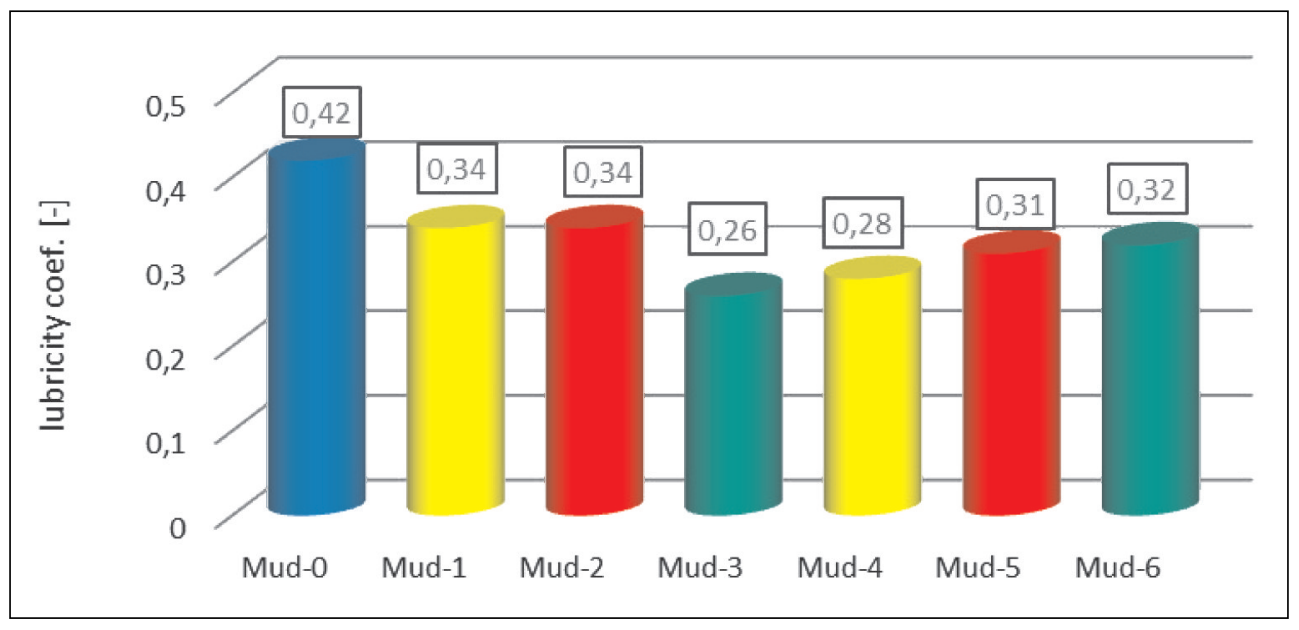

Fig. 11. Lubricity of tested mud

Lubricity rate of examined suspension decreases along with the ionic height for low copolymer concentrations. At high copolymer concentrations an opposite effect is observed (Fig. 11).

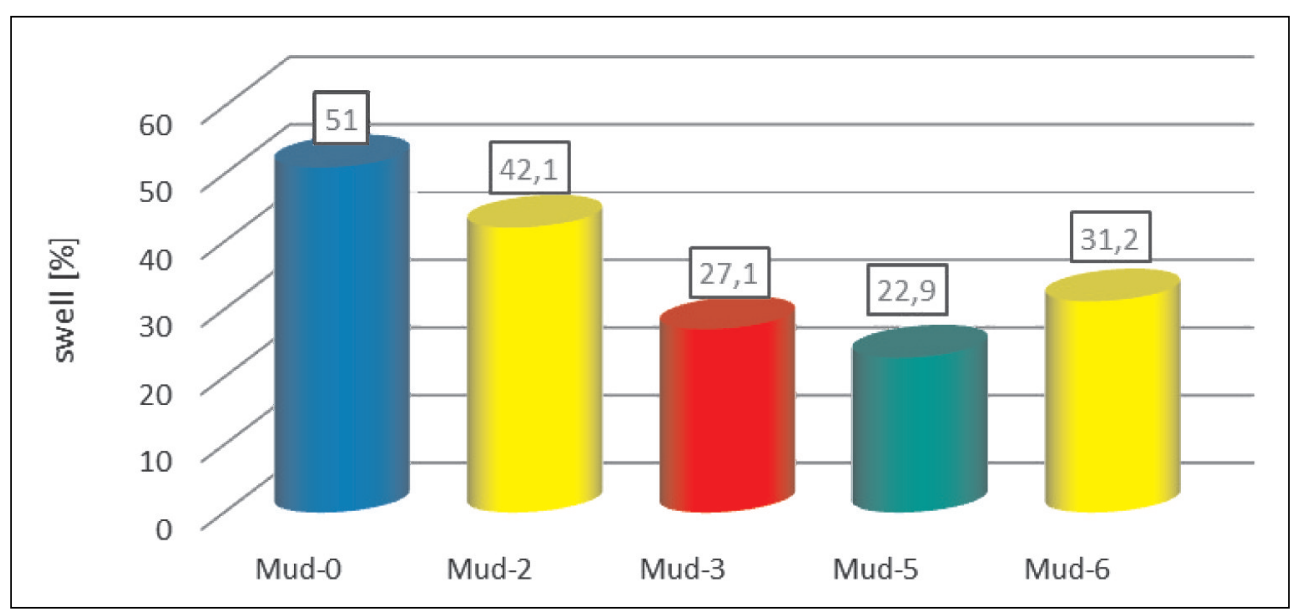

Fig. 12. Linear Swell Test of tested mud

Conducted LST examinations (Linear Swell Test) show that examined copolymers reduce the value of swelling Miocene shale (Fig. 12). At applying low concentrations of copolymers, swelling of clay rocks is reduced along with the ionic height of polymer. At high concentrations of polymers, the shale samples swells more for polymers with higher ionic. 


\section{SUMMARY}

Based on conducted examinations it was stated that the impact of ionic degree of synthesized copolymers poly(AAm-co-AMPSA) to bentonite suspension parameters is different and depends on the polymer concentration.

In low concentrations $(0.25 \% \mathrm{w} / \mathrm{w})$ the ionic height of copolymer poly(AAm-co-AMPSA) causes a decrease of flow limits, structural strength, lubricity rate and increased filtration. Studies have not shown the viscosity correlation (PV and AV) of examined suspension from ionic of copolymer.

In case of applying copolymers poly(AAm-co-AMPSA) in high concentrations $(1 \% \mathrm{w} / \mathrm{w})$ an increase in all values is observed (apart from the structural strength) of bentonite suspension parameters along with the ionic height of copolymer.

\section{REFERENCES}

[1] Bielewicz D.: Plyny wiertnicze. Wydawnictwa AGH, Kraków 2009.

[2] Bielewicz D., Bortel E., Witek E.: Polimery amfoteryczne w zastosowaniu do ptuczek wiertniczych. Wydawnictwa AGH, Kraków 2003.

[3] Bielewicz D., Bortel E.: Polimery w technologii ptuczek wiertniczych. Wydawnictwa AGH, Kraków 2000.

[4] API Specification 13B-2, 5th edition, April 2014. 